\title{
A Quasi-Experimental Study of Dengue Hemorhagic Fever Grade 1 and 2 Clinical Pathway Implementation in Universitas Sumatera Utara Hospital
}

\author{
Ivana Alona ${ }^{1}$, Juliandi Harahap ${ }^{2}$, Andike Aribi $^{3}$ \\ \{ivanaalona@gmail.com ${ }^{1 *}$,juliandiharahap@yahoo.com ${ }^{2}$, aribi13121986@gmail.com ${ }^{3}$ \} \\ ${ }^{1}$ Committee of Quality and Patient Safety, Universitas Sumatera Utara Hospital, Indonesia \\ ${ }^{2}$ Department of Public Health, Faculty of Medicine Universitas Sumatera Utara, Indonesia \\ ${ }^{3}$ Directorate of Medical Services, Universitas Sumatera Utara Hospital, Indonesia \\ *ivanaalona@gmail.com
}

\begin{abstract}
Clinical pathways are essential to control cost and quality performance. The data of its implementation in USU Hospital was absent. This study aimed to assess the compliance of DHF CP implementation on diagnostic, treatment and hospital cost. This study was using quasi-experimental design. An intervention of CP socialization was conducted in 2019. The data were obtained from CP, Medical Record, financial unit, and Hospital Information System. A total of 100 DHF grade 1 and 2 cases were analyzed using SPSS. We found that the intervention improved the compliance of intravenous solution $(\mathrm{p}=0.096)$, drugs $(\mathrm{p}=0.001)$; reduced hospital adjusted cost (Rp. 481,165.42, p=0.002), laboratory cost (Rp. 205,535, $\mathrm{p}=0.012)$ and $\operatorname{LOS}(0.64$ day, $\mathrm{p}=0.019)$. There was no statistical difference in laboratory test compliance $(p=0.3)$ and drug cost $(p=0.113)$ between the CP groups. In conclusion, the implementation of DHF CP improved the overall hospital cost and variance of drugs.
\end{abstract}

Keywords: DHF, hospital cost, clinical pathways, cost control, quality control

\section{Introduction}

Within recent 50 years, the incidence of Dengue Hemorrhagic Fever in South East Asia Region is increasing 30 times. [1] It was estimated that 3,97 billion people were at risk of dengue infection and inhibited in 128 endemic countries.[2] A number of 390 million infections occur every year and $70 \%$ of the infected people live in Asia. [3]

The World Health Organization data shows that Indonesia is at the first place in Asia and the second place after Brazil in 2004-2010. [1] According to the Indonesian Ministry of Health 2018, its incidence was fluctuating from 2010 to 2017 with the rate of $65.7,27.7,37.3,45.9,39.8,50.8,78.9$ and 26.1 per 100,000 populations, respectively. In 2017, 204,171 cases with 493 deaths. This number was significantly decreased from 2016 with 204,171 cases and 1,598 deaths. [4]

In North Sumatera, one of Indonesia province, DHF is still a major public health problem. The incidence was $18.5,19.8,21.2,24.1$, and 61.4 per 100,000 populations 
between 2012 and 2015, respectively. The incidence rate in 2016 was above the national indicator. [5] According to Medical Record Unit of Universitas Sumatera Utara (USU) Hospital, DHF was considered as one of the top 10 diagnosis in 2016, 2017, and 2018 [6].

As one of the hospitals which provide national health insurance system service, USU hospital should manage their service procedure in order to control financial and quality performance to meet the patient's demand. The service system should work optimally by using tools which is evidence based, providing detail and integrated instructions for caregivers. Clinical pathway (CP) is one of the tools that can facilitate the provision of the above aim.

$\mathrm{CP}$ is a structured integrated care plan which involves detail guidance based on evidence with measured outcome within certain time frame. It is used as a tool to identify differences that occur during the patient being treated [7]. It contains a clear and solid pattern that may be used as a reminder for the clinicians and other caregivers. Furthermore, it may improve critical thinking, develop interdisciplinary collaboration, provide optimal clinical outcome and decrease cost burden for patients and hospitals [8].

DHF grade 1 and $2 \mathrm{CP}$ has been designed by Department of Internal Medicine of USU hospital since 2006. However, the practice was unclear and inadequate. This study assessed the implementation of this CP in 2018 and 2019. We analyze the differences after the socialization intervention and include CP conducted in 2019.

\section{Research Method}

This was an analytical explorative study by using quasi-experimental design. We held an intervention by conducting DHF grade 1 and 2 Clinical Pathway socialization in early 2019. We observed data of DHF patients admitted in Universitas Sumatera Utara Hospital in 2018 and longitudinally followed the cases in 2019.

The study was conducted within 10 months from January to October 2019 at Universitas Sumatera Utara Hospital by obtaining data from Medical Record Unit, Verification and insurance Unit (financial unit for national health insurance participant), Hospital Technology and Information System, and Medical Committee.

The sample of this study is a total of 100 DHF grade 1 and 2 cases, each 50 cases were obtained from 2018 and 2019 data, respectively. The inclusion criteria of this study were DHF grade 1 and 2 cases from Internal Medicine department with BPJS membership (JKN participant). We excluded patients below 18 years old and severe DHF cases.

Data of DHF grade 1 and 2 patients admitted in 2018 was obtained from Medical Record unit. We assessed the data by confirming to the verification and insurance unit (financial unit for BPJS participant) and Hospital Information System for hospital cost of each patient. DHF grade 1 and 2 Clinical pathway forms were collected from Medical Committee. In 2019, we held DHF grade 1 and 2 CP socialization to the integrated caregivers and requested that the CP forms inserted in patient's Medical Record status. We observed the implementation longitudinally and matched the information provided on the CP forms by checking the Medical Record and Hospital Information System to assess the compliance of the integrated process, diagnostic examinations, therapy, and length of stay. The cost of accomodation, laboratory, drug, and medical intervention were 
provided in Hospital Information System. BPJS rates (National Health Insurance coverage) and total hospital cost were provided by verification and insurance unit.

The table below shows compliance indicators of the implemented DHF grade 1 and 2 CP in Universitas Sumatera Utara Hospital.

Table 1. Compliance indicators in DHF grade 1 and 2 Clinical Pathway

\begin{tabular}{ll}
\hline \multicolumn{1}{c}{ Variables } & \multicolumn{1}{c}{ Indicators } \\
\hline Compliance of laboratory tests & Hemoglobin, hematocrit, trombocyte, white \\
& blood count, clotting time, bleeding time * \\
& Ig M and Ig G anti Dengue** \\
Compliance of intravenous solution & Ringer Lactat* \\
Compliance of drugs & Paracetamol $10-15 \mathrm{mg} / \mathrm{kg}$ of body weight (IV)* \\
& Ranitidin $50 \mathrm{mg} / 12 \mathrm{hrs}(\mathrm{IV})^{* *}$ \\
& Ondansetron $4 \mathrm{mg} / 8 \mathrm{hrs}(\mathrm{IV})^{* *}$ \\
& Paracetamol $10-15 \mathrm{mg} / \mathrm{kg} \mathrm{of} \mathrm{body} \mathrm{weight}$ \\
& (oral)** \\
& Omeprazole $20 \mathrm{mg}($ oral)** \\
& Domperidon $10 \mathrm{mg}(\text { oral })^{* *}$ \\
\hline
\end{tabular}

* mandatory

**allowable

We adjusted the hospital cost by reducing total hospital cost with total accommodation price. The total accommodation price was obtained by multiplying LOS and accommodation rate (indicated by BPJS participant class) of USU hospital.

Table 2. Universitas Sumatera Utara Hospital accommodation rate

\begin{tabular}{cc}
\hline Room Class & Accomodation rate (Rp. per day) \\
\hline VIP & $500,000,-$ \\
1 & $250,000,-$ \\
2 & $150,000,-$ \\
3 & $100,000,-$ \\
\hline
\end{tabular}

Before the study was conducted, we obtained a health ethics permit from Ethics Committee of Medical Faculty Universitas Sumatera Utara No. 507/TGL/KEPK FK USU-RSIP HAM/2019.

The data were processed and analyzed using Microsoft Excell and SPSS with significant level of $95 \%$ and $\alpha$ of 0.05 . Chi square test was used to analyze categorical variables: compliance of laboratory test, solution, drugs, and LOS. Independent t test were applied to calculate mean difference for numeric scale variables: LOS, adjusted hospital cost, laboratory cost, and drug cost. 


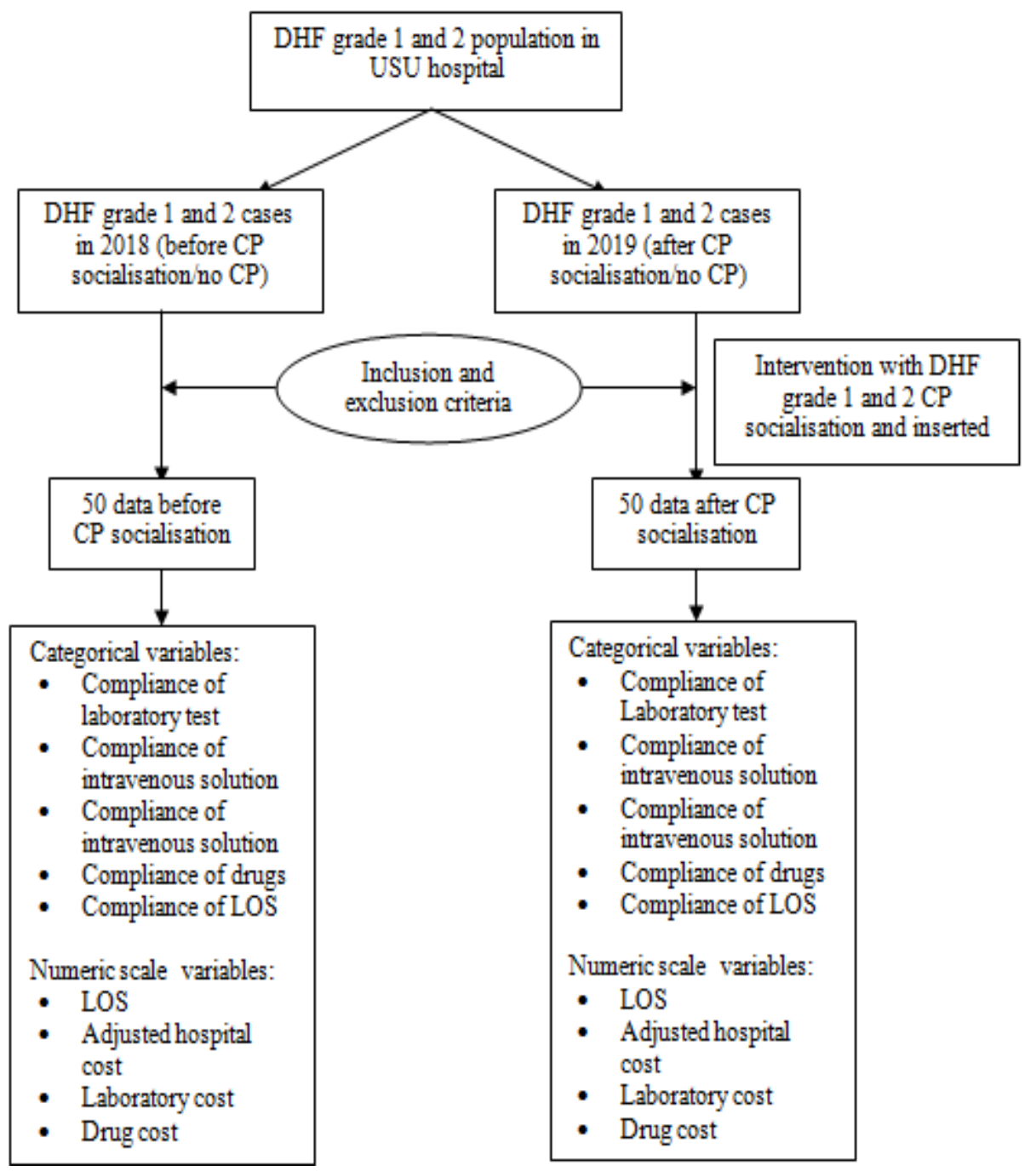

Fig.1. Study flow

\section{Results and Discussion}

This research was carried out from January to October 2019, with a total of 100 samples. We divided the data into two groups consisting of 'no CP' (50 data without $\mathrm{CP}$ ) and 'with $\mathrm{CP}$ '(50 data with $\mathrm{CP}$ intervention). 


\subsection{Caregiver Compliance towards process elements in DHF Grade 1 and 2 Clinical Pathway}

Table 3. Chi square test of laboratory test compliance among CP groups

\begin{tabular}{ccccc}
\hline \multirow{2}{*}{ Group } & \multicolumn{2}{c}{ Laboratory test compliance } & Total & p value \\
\cline { 2 - 3 } & no & yes & & \\
\hline no CP & $21(42 \%)$ & $29(58 \%)$ & $50(100 \%)$ & \\
with CP & $16(32 \%)$ & $34(68 \%)$ & $50(100 \%)$ & 0.3 \\
Total & $37(100 \%)$ & $63(100 \%)$ & $100(100 \%)$ & \\
\hline
\end{tabular}

Based on table 3, it was found that the proportion of laboratory test adherence was greater than those who did not comply either in no CP (58\%) and with CP group (68\%). There is no statistical different in laboratory test $(\mathrm{p}=0.3)$ between the two groups.

Table 4. Chi square test of Intravenous solution compliance among CP groups

\begin{tabular}{|c|c|c|c|c|}
\hline \multirow{2}{*}{ Group } & \multicolumn{2}{|c|}{ Intravenous solution compliance } & \multirow{2}{*}{ Total } & \multirow{2}{*}{ p value } \\
\hline & no & yes & & \\
\hline no $\mathrm{CP}$ & $22(44 \%)$ & $28(56 \%)$ & $50(100 \%)$ & \\
\hline with $\mathrm{CP}$ & $14(28 \%)$ & $36(72 \%)$ & $50(100 \%)$ & 0.096 \\
\hline Total & $36(36 \%)$ & $64(64 \%)$ & $100(100 \%)$ & \\
\hline
\end{tabular}

After the intervention, the compliance of intravenous solution using Ringer lactate was significantly increased $(\mathrm{p}=0.096)$. Before $\mathrm{CP}$ socialization, Ringer lactate was used in 28 patients $(56 \%)$. While after the intervention, it was used in $36(72 \%)$ patients.

Table 5. Chi square test of drugs compliance among CP groups

\begin{tabular}{lcccc}
\hline \multirow{2}{*}{ Group } & \multicolumn{2}{c}{ Drugs compliance } & Total & p value \\
\cline { 2 - 3 } & no & yes & & \\
\hline no CP & $37(74 \%)$ & $13(26 \%)$ & $50(100 \%)$ & \\
with CP & $21(42 \%)$ & $29(58 \%)$ & $50(100 \%)$ & 0.001 \\
Total & $58(58 \%)$ & $42(42 \%)$ & $100(100 \%)$ & \\
\hline
\end{tabular}

After the CP intervention, the caregiver's compliance in using indicated drugs mentioned in the CP was increased significantly $(\mathrm{p}=0.001)$. Before the socialization of $\mathrm{CP}$, compliance with drug use was only $26 \%$ and after the use of CP the compliance rate was $58 \%$. 


\subsection{Direct hospital cost of DHF grade 1 and 2 patients}

Table 6. Independent t-test of cost variables among CP groups

\begin{tabular}{lccccc}
\hline Cost variables & & n & mean \pm sd & $\begin{array}{c}\text { mean } \\
\text { difference }\end{array}$ & p value \\
\hline Laboratory cost & no CP & 50 & $540,015 \pm 478831.3$ & Rp. 205,535 & 0.012 \\
& with CP & 50 & $334,480 \pm 300293.7$ & & \\
Drug cost & no CP & 50 & $301,515.3 \pm 156536.8$ & Rp. 47,552.6 & 0.113 \\
Adjusted hospital & with CP & 50 & $253,962.68 \pm 140669.7$ & & \\
cost* & with CP & 50 & $2,248,200.9 \pm 673753$ & Rp. 481,165.4 & 0.002 \\
\hline
\end{tabular}

*adjusted hospital cost $=$ total hospital cost after adjusted with accommodation cost per day (based on BPJS class) and LOS

Using independent $\mathrm{t}$ test, there is a significant difference in laboratory costs after the socialization of DHF grade 1 and $2 \mathrm{CP}$. The $\mathrm{CP}$ intervention reduced the laboratory cost to Rp. 205,535 ( $\mathrm{p}=0.012$ ). Before the socialization of the $\mathrm{CP}$, the mean cost of laboratory tests was Rp. 540,015 ( $\mathrm{SD}=\mathrm{Rp} .47,8831.3)$. Whereas, after the socialization, it reduced to Rp. 334,480 ( $\mathrm{SD}=30,0293.7)$.

This study also showed a difference of Rp. 47,552.62 in drug cost in CP group compared to the group without $\mathrm{CP}$, but this finding was not significant $(\mathrm{p}=0.113)$.

There was a very significant difference of the adjusted hospital cost between 'with $\mathrm{CP}^{\prime}$ and 'no CP' group, with an amount of Rp. 481.165.42(p=0.002). The adjusted hospital cost referred in this study is after deducting the total hospital cost with accommodation variable. Accommodation variables are determined based on treatment class and LOS. The class of patient included in this study varied depending to their BPJS class. Other than that, USU hospital treatment cost was uniform.

\subsection{Length of Stay of DHF grade 1 and 2 patients}

\begin{tabular}{lccccc}
\multicolumn{6}{c}{ Table 7. Independent t-test of LOS among CP groups } \\
\hline \multicolumn{2}{c}{ Category } & n & mean \pm sd & $\begin{array}{c}\text { mean } \\
\text { difference }\end{array}$ & p value \\
\hline \multirow{2}{*}{ LOS } & no CP & 50 & $5.16 \pm 1.4$ & \multirow{2}{*}{640} & 0.019 \\
& with CP & 50 & $4.52 \pm 1.3$ & & \\
\hline
\end{tabular}

Based on the table above, there was a difference in the length of stay (LOS) of 0.64 days after implementing CP compared, in which this difference was statistically very significant $(\mathrm{p}=0.019)$.

\section{Discussions}

A clinical pathway serves as a method to gain a goal. It becomes as a tool to empower caregivers to put in balance between clinical and resource aspect of care. [9] However, a clinical pathway only functions as a guideline or map instead of mandatory procedures. It reflects the majority needed care and might not be applicable to all patients within defined population. [10] 
In our study, the use of DHF grade 1 and 2 clinical pathway cannot proof the difference of compliance aspects in laboratory examinations. In this study, the compliance of the caregivers of the laboratory test has greater proportion either before or after the CP socialization. Descriptively, we assume that most of the caregivers already aware of standard laboratory tests available in USU hospital for DHF grade 1 and 2 cases. Furthermore, after the socialization of the clinical pathway, the laboratory cost showed improvement. This implied that the $\mathrm{CP}$ socialization is successful in reducing the laboratory cost.

The implementation of DHF grade 1 and 2 Clinical Pathway showed that caregivers reduced the variation in the therapy aspects. After the intervention of CP socialization, the caregivers put more compliance in using Ringer Lactat as the intravenous solution. Furthermore, this study also found that the variation of drugs also decreased. Before the socialization of DHF grade 1 and $2 \mathrm{CP}$, the caregivers tended to add more treatment variation among DHF grade 1 and 2 patients. Our finding of average drug cost was reduced to Rp. 47,552, descriptively, although the difference was not significant.

Our study showed that after the socialization of CP, the LOS decreased to 4.52 days from 5.16 days. This finding was similar to many studies, [11][12][13][14 ]the implementation of clinical pathway shorten the length of stay (LOS). Munoz et al. showed that, among 487 hip arthroplasty patients, there was significant decrease in LOS, which cut from a mean of 19.41 days to 10.12 days and 4.5 days before surgical stay to 1.08 days [12]. The implementation of clinical pathways in the field of laparoscopic surgeries at a Japanese hospital implicated a significant reduction in hospital length of stay [13]. LOS was reduced after implementation of $\mathrm{CP}$ among congested heart failure patients [14].

In this study, the hospital cost after adjusted with accommodation cost showed significant improvement. After the clinical pathway socialization, the DHF grade 1 and 2 cases dropped from Rp. 2,248,200.9 to Rp. 1,767,035.5. The CP implementation is significantly cut Rp. 481,165.4 cost in average for the hospital cost. This may indicate that the hospital cost in DHF patients in previous period was not regularly controlled and lacked of coordination compared to the $\mathrm{CP}$ implementation era.

\section{Conclusions}

Implementation of clinical pathway has positive impacts in reducing treatment variation, length of stay, and hospital cost. In our study, laboratory variation after the socialization of DHF grade 1 and $2 \mathrm{CP}$ was not different. We assume that the caregivers already aware of standard laboratory tests available in USU hospital. We did not anticipate for the existence of comorbidities in this study. It is expected that the hospital should intensify the monitoring and documentation of the implementation of DHF Grade 1 and 2 Clinical Pathway. Further study should explore other aspects including comorbidity and patient outcome to assure the effectiveness of the $\mathrm{CP}$ implementation. 


\section{Acknowledgments}

The authors wish to acknowledge Universitas Sumatera Utara Rector and Chief of Research Institution for the support of this study through Talenta Universitas Sumatera Utara Project under the Hospital Development Research Scheme Number: 492/UN5.2.3.1/PPM/KP-TALENTA USU/2019; as well as Universitas Sumatera Utara Hospital for the cooperation and authorities.

\section{References}

[1] World Health Organisation. Global strategy for dengue prevention and control 2012-2020. (2012).

[2] Brady OJ, et. al. Refining the global spatial limits of dengue virus transmission by evidence-based consensus. PLoS Negl Trop Dis. (2012).

[3] Bhatt S1, Gething PW, Brady OJ, Messina JP, Farlow AW, Moyes CL, Drake JM, Brownstein JS, Hoen AG, Sankoh O, Myers MF, George DB, Jaenisch T, Wint GR, Simmons CP, Scott TW, Farrar JJ HS. No Title. Nature. 2013).

[4] Indonesian Ministry of Health. Indonesian Health Profile 2017. ( 2018).

[5] North Sumatera Provincial Health Office. A surveillance meeting of DHF and other Arbovirus for strengthening Puskesmas Officers in District. (2018).

[6] Medical Record Unit of Universitas Sumatera Utara Hospital. Top 10 Diagnosis in 2018. (2018).

[7] Firmanda, Doddy. Clinical Risks Management and Patient Safety. Medical Committee of Fatmawati Hospital. Jakarta. (2005).

[8] Holloway, Nancy Meyer. Medical Surgical Care Planning. Lippincott Williams \& Wilkins. Orinda, California. (2004).

[9] Degeling P, Maxell S, Kennedy J, Coyle B: Medicine, management, and modernisation: a "dansa macabre"?. BMJ. (2013).

[10] Cheah, J. Clinical Pathways - An Evaluation of its Impact on the Quality of Care in an Acute Care General Hospital in Singapore. Singapore Med Journal. (2000).

[11] Mauerhan DR, Lonergan RP, Mokris JG, Kiezak GM. Relationship between length of stay and dislocation rate after total hip arthroplasty. Journal Arthroplasty. (2003).

[12] Munoz, J., Garcia, D., Perez, R., and Sanjurjo, M. Clinical pathway for hip arthroplasty six years after introduction. International Journal of Health Care Quality and Assurance. (2006).

[13] Uchiyama, K., Takifuji, K., Tani, M., Onishi, H., and Yamaue, H. Effectiveness of the clinical pathway to decrease length of stay and cost for laparoscopic surgery. Surgery Endoscopy (2002).

[14] Ranjan, A., Tarigopula, L., Srivastava, R., Obasanjo, O., and Obah, E. Effectiveness of the clinical pathway in the management of congested heart failure. Southern Medical Journal. (2003). 